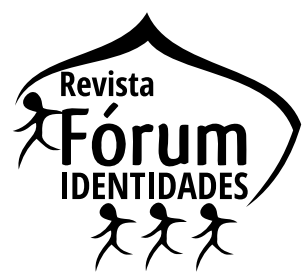

\title{
DAS FRANJAS DA OBRA AOS SENTIDOS DO TEXTO: AS NARRATIVAS DE PEPETELA ${ }^{1}$
}

\section{FROM THE FRINGES OF THE WORK THE MEANINGS OF THE TEXT: NARRATIVES OF PEPETELA}

\author{
Jeferson Rodrigues dos Santos²
}

\begin{abstract}
Resumo: O presente texto tem como objetivo analisar as estratégias discursivas e textuais presentes em Mayombe (2013 [1980]) e O planalto e a estepe: Angola, dos anos 60 aos nossos dias. A história real de um amor impossível (2009), de Pepetela, no trânsito paratexto, texto e contexto. À luz da noção de "paratexto autoral”, de Gérard Genette (2009 [1987]), articulam-se o nome do autor, o título e a dedicatória à instância narrativa e ao espaço. Como o paratexto coloca-se em relação ao texto, o pseudônimo Pepetela orienta a ótica para os narradores, e o título e a dedicatória suscitam o espaço. Assim, tanto os narradores quanto as geografias espaciais conectam-se ao eixo comum nas duas obras: a convivência entre diferentes grupos e sujeitos e suas diversas formas sociais e culturais.
\end{abstract}

Palavras-chave: Paratexto autoral. Pepetela. Instância narrativa. Geografias literárias. Imaginário cultural angolano.

\begin{abstract}
The present text aims to analyze the discursive and textual strategies present in Mayombe (2013 [1980]) and O planalto e a estepe: Angola, dos anos 60 aos nossos dias. A bistória real de um amor impossivel (2009), by Pepetela, in the transit of paratext, text and context. In the light of the notion of "authorial paratext", by Gérard Genette (2009 [1987]), the name of the author, the title and the dedication to the narrative instance and the space are articulated. As the paratext is placed in relation to the text, the pseudonym Pepetela guides the view towards the narrators, and the title and dedication raise the space. Thus, both the narrators and the spatial geographies are connected to the common axis in the two works: the coexistence between different groups and subjects and their various social and cultural forms.
\end{abstract}

Keywords: Author's paratext. Pepetela. Narrative instance. Literary Geographies. Angolan cultural imaginary.

\footnotetext{
${ }^{1}$ Artigo recebido em 16 de agosto de 2021 e aceito para publicação em 29 de setembro de 2021.

2 Doutorando em Estudos Literários no Programa de Pós-Graduação em Letras (PPGL) da Universidade Federal de Sergipe (UFS). E-mail: jr.triangular@gmail.com. ORCID: https://orcid.org/0000-0002-8808-2690.
} 


\section{Estabelecendo o trânsito}

O ano de 1961 contextualiza o cenário em torno das histórias narradas em Mayombe (2013 [1980]) e O planalto e a estepe: Angola, dos anos 60 aos nossos dias. A história real de um amor impossivel (2009), de Artur Carlos Maurício Pestana dos Santos - Pepetela. Em Angola, o período representa a manifestação do sentimento nacionalista. Há uma consciência nascida no bojo dos movimentos anticoloniais, os quais, por seus diversos núcleos, exercem um percurso de fora para dentro na construção dos modos de ser, pensar e agir. Não à toa, valendo-se das experiências de países como Argélia e Marrocos, a Casa dos Estudantes do Império (CEI) torna-se o centro das ideias nacionalistas pela independência de Angola. A principal delas propõe o Marxismo e sua vertente socialista como orientação ideológica, que, para uns, é uma alternativa à opressão e, para outros, um modelo problemático por não levar em conta as especificidades das histórias locais.

Mayombe ${ }^{3}$, narrativa escrita entre 1970 e 1971, publicada em 1980 em Angola e em 1982 no Brasil, enreda o período em que as mobilizações pró-independência influenciaram no cenário político e cultural do país. $O$ planalto e a estepe $e^{4}$, por sua vez, publicada em 2009, tanto em Portugal quanto no Brasil, também tem como pano de fundo a luta pela independência angolana, sob o ponto de vista, agora, de uma análise das transformações desde os movimentos de libertação angolana até o pós-guerra civil. A cidade e a floresta são dois espaços, fictícios/inventados ou geograficamente concretos, presentes na literatura angolana. Enquanto esta é representada como espaço simbólico não submetido às ordens da colonialidade, de valorização das raízes culturais e, durante a Guerra de Libertação, de base militar dos guerrilheiros, aquela é o lugar das formas de controle colonial e dos encontros e contatos entre povos e culturas.

Trata-se de obras inseridas na perspectiva de escritas africanas de língua portuguesa na produção de uma literatura própria frente ao cânone ocidental. Há, nesse sentido, o posicionamento de uma sensibilidade revolucionária e decolonial de Pepetela na composição delas. Ou melhor, o escritor angolano articula recursos textuais e discursivos, além de imaginários ideológicos e culturais diversos, ao mesmo tempo que trata do debate social e cultural na sociedade angolana. Tais perspectivas são apresentadas sob a moldura da obra literária, que começa a ser legitimada, em termos de definição, nas margens dos textos: os paratextos. Assim, partindo do "paratexto autoral", delimitado por Gérard Genette (2009 [1987]), especificamente

\footnotetext{
3 Dividida em cinco capítulos e epílogo: "A Missão", "Base”, “Ondina”, “A Surucucu”, "A Amoreira” e “Epílogo”. ${ }^{4}$ Dividida em oito capítulos e epílogo: "Os Rochedos da Tundavala”, "A Grande Viagem”, "Luar em Moscovo”, "Contra uma Porta de Pedra”, “Regresso a África”, "As Guerras e Os Silêncios”, “Nunca Digas Nunca”, “A Escolha” e “Epílogo”.
} 
nome do autor, título e dedicatória, a hipótese interpretativa deste texto é a seguinte: os elementos paratextuais definidos e controlados pelo autor orientam a posição da autoria e a composição do texto literário.

A escolha pelo "paratexto autoral" se dá com vistas ao objetivo deste texto: analisar as estratégias usadas nas narrativas para o trânsito do texto ao contexto, deste para aquele (GENETTE, 2009 [1987], p. 15). Por serem os paratextos discursos que comandam a leitura, os narradores e os espaços são os elementos da narrativa privilegiados nesta abordagem. Dessa forma, organizaremos o percurso deste modo: ao situar a definição de paratexto para refletir acerca do nome do autor e sua posição ideológica, parte-se para a análise da instância narrativa e do espaço na configuração de recursos literários, lugares discursivos e imaginários culturais.

\section{Nome do autor, “Autor-Criador”: da pessoa à instância narrativa}

O paratexto ocupa um espaço fronteiriço da relação com o texto, uma vez que o acompanha, o estabelece como obra e o insere na perspectiva comunicativa. Por exemplo, a capa, a contracapa, o título e o nome do autor constituem o livro como objeto. São escolhas do autor ou do editor na constituição de um "lugar privilegiado de uma pragmática" e um propósito estético ligado a "uma estratégia" (GENETTE, 2009 [1987], p. 10). Portanto, o paratexto indica o vínculo transtextual e, em consequência, guia formas de interpretar o texto.

A zona fronteiriça paratextual demanda os modos de negociação de sentidos. Ela coloca em relação o "dentro" e o "fora", isto é, o posicionamento discursivo junto ao texto e o que se diz sobre o texto sem estar incorporado a ele, respectivamente. São, pois, traços correspondentes ao peritexto e ao epitexto. Este não está anexado à obra, podendo ser público (entrevistas, colóquios etc.) ou privado (cartas, diários etc.), e aquele circula dentro do espaço da obra (nome do autor, título, dedicatória, epígrafes etc.). Ambos, como discursos sobre o texto, localizam-se nas margens e, em certa medida, situam a partilha de um mesmo ponto de vista.

Segundo Genette (2009 [1987], p. 16), a funcionalidade paratextual "pode comunicar uma mera informação [...]; pode dar a conhecer uma intenção ou uma interpretação autoral e/ou editorial". Caminha, também, no horizonte do leitor à medida que desperta ideias acerca do texto ou protocolos de leitura. O que se tem é seu caráter provisório, e, com efeito, por um lado, a função do paratexto pode não ultrapassar os limites editoriais, mas, por outro, pode trazer artifícios ligados à construção do texto literário. 
Sob essas perspectivas, este trabalho propõe o paratexto como elemento significante do texto. É um item integrado ao texto que carrega informação ou comentário e o direciona pelo ângulo transtextual. Portanto, tendo em vista o mecanismo da recepção do texto literário e o papel movente e relacional do paratexto, ocupa-se aqui do "paratexto autoral", especificamente nome do autor, título e dedicatória, na análise em tela das narrativas pepetelianas.

O título e o nome do autor são elementos de acesso imediato devido ao destaque já na capa do exemplar. O nome do autor é indispensável à circulação do texto em forma de livro, tendo como função, em primeira instância, indicar quem escreveu a obra. Além de determinar a quem pertence o texto, sugere sua aproximação com o sujeito histórico e literário designado pelo nome. Para isso, em diálogo com Mikhail Bakhtin (2014), o nome do autor promove o vínculo do texto com o contexto histórico e cultural, visto no espaço e no tempo, o "autor-pessoa": assina a obra e organiza todas as vozes na construção do artístico a partir de uma voz criativa que, em torno do múltiplo e do heterogêneo, articula todas as vozes sociais (BAKHTIN, 2014, p. 104).

Esse nome vai além da pessoa empírica e adentra as representações históricas, culturais e literárias. O "autor-pessoa" se assemelha à "função contratual" 5 designada por Genette (2009 [1987], p. 42), e, com isso, o texto é lido pelo lugar simbólico ocupado pelo autor. Nesse sentido, a categoria nome do autor não corresponde ao nome de registro de Artur Carlos Maurício Pestana dos Santos. O pseudônimo exerce diversas funções, mas, neste caso, tem a tarefa de propor um caráter literário ao autor que torna possível seu projeto literário. Pepetela significa "pestana" em quimbundo. Trata-se de um pseudônimo de guerrilha que indaga as referências portuguesas do seu nome e se coloca diante das línguas nacionais.

Pepetela articula uma ruptura ideológica e uma escrita literária movida pela narração sobre a nação e a sociedade. A partir dessa posição, um dos recursos estéticos explorados é a instância narrativa - os narradores. Para tanto, com base em Jeanne Marie Gagnebin (2006, p. 54), pensa-se o narrador-trapeiro, ou seja, personagem que, no cerne da marginalidade e anseio de não perder nada, recolhe "[...] tudo aquilo que é deixado de lado como algo que não tem significação, algo que parece não ter nem importância nem sentido, algo com que a história oficial não sabe o que fazer.”. Em Mayombe, a instância narrativa localiza-se

\footnotetext{
5 "O nome do autor cumpre uma função contratual de importância muito variável conforme os gêneros: fraca ou nula na ficção, muito mais forte em todas as espécies de escritos referenciais, nas quais a credibilidade do testemunho, ou de sua transmissão, se apoia amplamente na identidade da testemunha ou do relator" (GENETTE, 2009, p. 42-43). Em outras palavras, no caso do pseudônimo, como implica a transferência do nome verdadeiro para o nome inventado, abre espaço para a leitura a partir da identidade sugerida pelo nome.
} 
nas ações de um grupo de guerrilheiros na luta pela libertação do jugo colonial português. Como narradores-trapeiros, eles compõem o testemunho das diversas problemáticas enfrentadas pelo povo angolano.

A história é contada em torno de dois eixos, a saber: um narrador em terceira pessoa e outros narradores em primeira pessoa. Eles se comprometem com a seguinte missão: sensibilizar o povo angolano para o confronto com o inimigo real (colonizador) e a superação das diferenças. As vozes em primeira pessoa tensionam o que são plano e ação. Mundo Novo, por exemplo, defende a teoria marxista, ao passo que Muatiânuva carrega a herança de alguém nascido no contexto de misturas. Há, com isso, a imagem de convivência no mesmo espaço entre grupos e sujeitos sociais diversos.

Para tanto, entra em cena a voz em terceira pessoa que, ao relatar o caso entre Ondina e André, questiona os valores das pessoas que participam das bases do projeto de nação. Ao mesmo tempo, os preceitos considerados ideais são do Comissário, um "miúdo", como diz o Comandante Sem Medo. Na verdade, observa-se que as transferências de narração projetam um novo homem - de Comissário a João Comissário Político -, capaz de promover as rupturas necessárias à manutenção do projeto de nação: uma sociedade de homens livres. Note-se: "Lutamos, que era Cabinda, morreu para salvar um Kimbundo. Sem Medo, que era Kikongo, morreu por um Kimbundo. É uma grande lição para nós camaradas." (PEPETELA, 2013 [1980], p. 244).

“Eu, o narrador, sou...”. Essa expressão carimba a introdução das vozes em primeira pessoa. Algumas compreensões derivam dessa marcação. Uma delas toca na abertura à tradição oral angolana, uma vez que a presença dos discursos retrata o questionamento sobre narrar uma identidade nacional sem cair no paradigma de valorização étnica. A outra trata da passagem de foco narrativo no texto construído por narrativas individuais que se conectam à narrativa coletiva: pontos de vista sobre os conflitos entre angolanos e portugueses na floresta Mayombe. Assim, discursivamente expressa pelo "sou", enreda-se a possibilidade da individualidade no jogo das pluralidades de vozes em consonância com a ideia de comunhão e partilha.

Ademais, as narrações em primeira pessoa assinalam um procedimento bastante presente nos textos pepetelianos: dar voz aos silenciados. De modo claro, no texto em análise, as falas são marcadas em itálico, sem qualquer movimento de discurso indireto livre. Isso significa, pois, a inversão da lógica de silenciamento no período colonial e a retomada do direito de fala e representação. São vozes presentes em todos os capítulos que, além do debate contra o colonizador, refletem sobre racismo, tribalismo, planejamentos e ações. Nesse 
sentido, o fundamento é a diferença atravessada nas vozes ${ }^{6}$. Note-se um exemplo a partir da fala do Comandante Sem Medo: “[...] Os meus guerrilheiros não são um grupo de homens manejados para destruir o inimigo, mas um conjunto de seres diferentes, individuais, cada um com as suas razões subjetivas de lutar e que, aliás, se comportam como tal.” (PEPETELA, 2013 [1980], p. 231).

O que se vê é a figuração do caleidoscópio de vozes na confluência de povos e culturas. Uma sugestão da existência das contradições no espaço coletivo. Não à toa, deslocando a percepção de que os povos devem ser imaginados em torno de uma unidade cultural, propõe, com a metáfora do Sem Medo (Ogum, o Prometeu Africano), o reconhecimento da heterogeneidade na realidade narrada.

Não se trata de propor a heterogeneidade sem problematiza-la. Tal assertiva abre espaço para o narrador n'O planalto e a estepe, haja vista as travessias de Júlio, o narrador-personagem, conectadas ao narrador-trapeiro. Este narrador traz uma consciência crítica tanto da sua própria história como das outras histórias (GAGNEBIN, 2006, p. 54). Também, apresenta a oralidade ancestral, aquele que tanto viaja quanto fica na terra e valoriza a tradição. Sua característica de estar sempre em trânsito não se desvincula da referência à herança oral. Veja-se: "O tempo é um atleta batoteiro, toma drogas proibidas, corre mais que todos. E quanto mais o quisermos agarrar, porque resta pouco, mais ele corre." (PEPETELA, 2009, p. 13).

A propósito desse trecho, problematiza-se o tempo e, ao fazê-lo, se inclui o modo como os velhos kimbos o compreendem. Essa maneira reconhece o tempo na tradição e no espaço rural, de modo que direciona a crítica ao espaço urbano e à ideia de rapidez do tempo. Não só isso, mas também ao entendimento de que os saberes orais acontecem no tempo da contemplação, cuja sabedoria é transmitida por provérbios. Eis alguns exemplos dos vários que aparecem no texto: "O valor da pele é o seu calor" (2009, p. 12); “O homem só gosta da diferença, sobretudo a que o favorece" (2009, p. 22).

Para tanto, os traços da oralidade são articulados à abordagem dos saberes ancestrais e da religiosidade em alguns momentos da narrativa. O primeiro é o relato de Júlio no comando da tropa durante a luta de libertação e independência de Angola. Ele usa o saber tradicional e conta sobre o feitiço que "fechou" seu corpo para o combate. O segundo toca nas histórias do diálogo

6 Teoria e Lutamos sofrem racismo e têm de se mostrar superiores. Milagre e Chefe das Operações impõem o racismo. Mundo Novo é o seguidor da teoria marxista. Muatiânuva proclama as misturas como integração entre os sujeitos. André busca as vantagens individuais provenientes do jogo político. Chefe do Depósito mantém sua postura honesta durante a revolução. Chefe das Operações passa a confiar no valor dos povos diversos. Lutamos dá a vida como exemplo de superação dos preconceitos. Comissário se transforma ao longo da narrativa. Ver: SILVA, Rejane Vecchia da Rocha; MATTOS, Tatiane Reghini. Mayombe: presença da guerra, perspectiva histórica e memória na construção do romance. CERRADOS: Revista do Programa de Pós-Graduação em Literatura, n. 40, ano 24, p. 289-302, 2015. 
com o marido de Sarangerel; esta pede a conversa entre os dois como se fossem homens em conflito. Para isso, a narrativa retoma as lições do Kimbo na resolução do conflito: o leão e o elefante, aconselhados pelo cágado, dialogam e evitam o combate. Assim, por essa articulação com a oralidade, há o mesmo movimento feito em Mayombe: o que se tem de tensão na história individual pode ser resolvido na história coletiva.

\section{As geografias entre títulos e dedicatórias}

O título da obra oferece ao texto uma abertura interpretativa. É um "ato de batismo" (GENETTE, 2009 [1987], p. 76) que nomeia o objeto (a obra) e, em consequência, o coloca em relação com outros. Sua função mais evidente é antecipar e situar o texto principal como um convite à leitura do conteúdo, seja de modo direto ou simbólico. Nessa ótica, portanto, os batismos de Mayombe e $O$ planalto e a estepe: Angola, dos anos 60 aos nossos dias. A bistória real de um amor impossível apontam para espaços representados na construção de geografias simbólicas de identificação e pertencimento.

Em concordância com Nazir Ahmed Can (2020), a ideia de espaço aqui tem relação com escritas literárias sobre os espaços ficcional/inventado ou geograficamente concreto, tendo em vista a percepção de suas formas, funções e tradições articuladas à composição das narrativas pepetelianas. A espacialidade é reconhecida como performativa que se faz em relação aos narradores e personagens. No tocante ao nome que dá título à obra, Mayombe, Carmem Lúcia Tindó Secco (2008) diz que é um termo do Congo que significa "feitiço" e "macumba", e um mayombeiro é o responsável pelos atos. Na separação etimológica dos termos, "ma" (prefixo) expressa "reino" e se liga a "iombe" (substantivo), nome de um dos povos de Cabinda. Esse substantivo tem uma aproximação fonética com "lombe", o rio Lombe, propondo, com efeito, a conexão da floresta dos ancestrais com as flores da luta e da reconquista (SECO, 2008, p. 53).

$\mathrm{O}$ enredo em Mayombe transcorre em dois espaços. O urbano, no retrato de Dolísie, povoado mais próximo da floresta tropical de Cabinda, aparece poucas vezes e, quando surge, é fonte de críticas sociais. A floresta, tendo em vista o título da obra, é o centro das ações, um ambiente no qual a ambiguidade é a força motriz: junta os iguais e contrapõe outros sujeitos; terra protetora e repleta de situações divergentes. Note-se: "A mata criou cordas nos pés dos homens, criou cobras à frente dos homens, a mata gerou montanhas intransponíveis, feras, aguaceiros, rios caudalosos, lama, escuridão, Medo. [...] a mata curvou-se em abóbada, e a mata estendeu-lhes a sombra protetora, e os frutos [...].” (PEPETELA, 2013 [1980], p. 68). 
O horizonte do lugar é parte da compreensão sugerida por Stuart Hall (2015, p. 41), pois “o 'lugar' é específico, concreto, conhecido, familiar, delimitado: o ponto de práticas sociais específicas que nos moldaram e nos formaram e com as quais nossas identidades estão estreitamente ligadas.”. Imagina-se um lugar possível do sentimento de pertença. Além da ambiguidade, com os conflitos entre angolanos e portugueses, a floresta Mayombe é metáfora de um espaço utópico. Protegida das influências externas, é um lugar viável à permanência de quem nela vive. Não apenas isso, mas também é capaz de produzir vivências e harmonia entre as diferenças.

No caso de O planalto e a estepe: Angola, dos anos 60 aos nossos dias. A bistória real de um amor impossivel, observam-se o título e o subtítulo. O primeiro localiza o planalto Sul (Huíla, Serra da Chela, Rochedos da Tundavala) e a estepe Mongólia (plana, árida e calcária). Eles não são colocados como opostos; são, haja vista a conjunção " $\mathrm{e}$ ", vinculados à representação das confluências entre espaços diversos. O segundo, o subtítulo, delimita o jogo entre o ficcional e o real e o período da narrativa, isto é, da guerra de libertação até a guerra civil. Junta, assim, personagens, tempo e espaço, de modo que o planalto está relacionado ao azul dos olhos de Júlio e a estepe, ao castanho dos olhos de Sarangerel. Então, sob esse modo de ver, a entrada no azul denota pensar Angola, a infância e a juventude de Júlio, o narrador-personagem.

Ao azul está voltada a voz em primeira pessoa. A narrativa apresenta uma autobiografia de Júlio e um percurso existencial frente aos constantes deslocamentos das viagens até o amor, os quais enredam as histórias individual e coletiva, local e nacional. Ora, em articulação com Rita Chaves (1999, p. 219) quando diz que "o espaço [...] se eleva e atua como elemento de forte significado", compreende-se a presença desse elemento na problematização das identidades: o espaço angolano de encontros e tensões sociais e culturais. Desde Angola, passando por Portugal, Marrocos, Rússia, Argélia, Mongólia, Cuba, até retornar a Angola, a história local se relaciona com a global: "Os continentes são convenções, apenas existem terras separadas por mares." (PEPETELA, 2009, p. 30). Apesar das aproximações continentais, Angola (Sul) é o espaço de referência; portanto, lugar dos saberes locais e sensibilidades de mundo na contramão do contexto de colonialidade moderno, urbano e capitalista.

A dedicatória é outro elemento paratextual de encadeamento com o texto literário. Conforme argumenta Genette (2009 [1987], p. 123), o ato de dedicar a obra a alguém carrega uma certa ambiguidade porque supõe alguns destinatários: a pessoa, a instituição homenageada ou o leitor. Uma vez publicada a obra e nela há dedicatória, é como se o escritor comunicasse: "Diga ao leitor que dedico este livro a Fulano.” (GENETTE, 2009 [1987], p. 123). Diante dessa proximi- 
dade com o leitor, a dedicatória é um artifício de legitimação e abertura da obra, seja para colocar o escritor à volta de perspectivas consagradas, manifestar determinada influência literária ou garantir mecanismos estéticos e ideológicos. Como função, a dedicatória indica uma ação de reconhecimento e agradecimento no contexto das relações sociais, intelectuais ou afetivas do escritor. E, extrapolando a zona limite da informação, sugere algo sobre o texto.

Por esse ângulo, a dedicatória integra-se ao texto, e os sentidos dessa vinculação são atualizados na análise. Mayombe é o deus que tanto protege quanto tem o poder de transformar e criar um lugar de união entre sujeitos, além de estabelecer formas de identificação para viverem nela e dela. Segue a dedicatória: "Aos guerrilheiros do Mayombe,/ que ousaram desafiar os deuses/ abrindo um caminho na floresta obscura,/ Vou contar a história de Ogum,/ O Prometeu africano.” (PEPETELA, 2013 [1980], p. 9).

Como se vê, o percurso narrativo introduz a ótica de que o espaço é articulado na história, ou seja, está vinculado à focalização narrativa. Nessa representação do espaço têm a tensão e os conflitos, uma vez que há, na esteira de Luís Brandão (2013, p. 67), “[...] a radicalização do significado da ação de transpor, a qual passa a ser entendida como de interferência, dinamização, provocação, desestabilização. Trata-se, portanto, de uma ação política.”. A presença da natureza é privilegiada na narrativa. Nela são possíveis o diálogo, as tensões e as transformações de seus elementos, na medida em que é metáfora do espaço de profundidade africana, onde os diferentes são reconhecidos e todos são tratados como iguais. O que os une são a busca pela liberdade e a formação de uma nação baseada na partilha de valores e no respeito à diversidade sociocultural. Veja-se: “O Mayombe tinha criado o fruto, mas não se dignou mostrá-lo aos homens: encarregou os gorilas de o fazer, que deixaram os caroços partidos perto da Base, misturados com as suas pegadas.” (PEPEPTELA, 2013 [1980], p. 67).

O início da dedicatória - "aos guerrilheiros do Mayombe" - manifesta o espaço heroico-mítico e de guerra. Ao mesmo tempo que simboliza a heterogeneidade no meio da paisagem uniforme, há a peleja contra o colonialismo e a corrupção, o racismo e o tribalismo. Por isso, em diálogo com Chaves (1999, p. 46), a floresta é uma metáfora da luta contra o sistema colonial. Mais que isso, ela é um espaço humanizado e politizado. Humanizado em razão da esperança na sensibilidade em identidades e seus diálogos culturais, sociais e políticos; politizado porque os marginalizados assumem as performances discursivas para falar e reagir na reivindicação e no reestabelecimento do território.

Os enfrentamentos na floresta são gestos de reconquista dos bens e valores culturais, de abrigo e interação entre grupos e sujeitos: “O comissário apertou-lhe mais a mão, querendo transmitir-lhe o sopro de vida. Mas a vida de Sem 
Medo esvaía-se para o solo do Mayombe, misturando-se às folhas em decomposição.” (PEPETELA, 2013 [1980], p. 243). Assim, as relações conflituosas entre os homens e o deus-mayombe atravessam seus corpos e os liga à terra; só assim, na perspectiva da narrativa, se consolidam a luta pela comunhão angolana e os grupos explorados, oprimidos ou excluídos.

Por seu turno, a dedicatória d'O planalto e a estepe é a seguinte: "Para a Suren/ Em memória do Piricas" (PEPETELA, 2009, p. 7). Mediante a presença da ironia, ela conjectura a ligação pessoal, o conhecimento da história e a determinação dos deslocamentos. As passagens por diversos espaços retratam o sentido de impossibilidade, evidente, pois, com as adversidades da "união" entre Júlio e Sarangerel em não vivenciarem o amor. A família da personagem não aceita o relacionamento dela com um estrangeiro. O casal tenta o casamento pelo "internacionalismo proletário" (2009, p. 64), mas somente o filho é capaz de efetivar a união entre povos. Isso, no entanto, não acontece porque Sarangerel é levada para a Mongólia a mando do pai, desenvolvendo, nessa parte da narrativa, a crítica ao não reconhecimento democrático da presença das diferenças. Veja-se:

\footnotetext{
Sabem o que é sentirem-se apagados, escorraçados da história? Talvez não saibam, poucos hoje em dia viveram as experiências de colonizados ou de escravos, que significa exatamente a não existência, o terem sido de repente apagados do mundo, da vida, da memória, transmutados em não seres-humanos. (PEPETELA, 2009, p. 100).
}

O retorno de Júlio a Angola é outro momento importante nos deslocamentos. Antes passa pelo Congo na luta armada ao fim da Guerra Civil, faz guerrilha na Cabinda, no norte, como Sem Medo e seu grupo, de modo que manifesta o elo com a floresta Mayombe. Ele entende a guerra como fratricida porque, para a liberdade, existe o risco da vida na terra. Em Mayombe, contudo, a guerra é retratada como movimento de reconhecimento dos bens e valores culturais, de abrigo e interação entre diversos grupos e sujeitos. Mesmo diante dos contrapontos, Júlio se assume como guerrilheiro, destacando-se pela dependência com o território e os saberes tradicionais. O seu nome de guerrilha é Alicate, que significa "retorce, verga, entorta", metaforicamente interpretado por duas vias em torno do mesmo eixo: os negros eram batizados com nomes de objetos, e, por meio do tom irônico na narrativa, esse nome alude aos problemas sofridos pelos negros no Sul.

Para mais, os deslocamentos espaciais se ligam à passagem do tempo: do movimento de libertação ao pós-independência. Neste, há o retorno de Júlio ao Sul, agora como um general que se vale da patente para retomar o contato com Sarangerel em Cuba. Essa viagem ao encontro dela representa o espaço socialis- 
ta na junção dos laços rompidos. Enredam-se, pois, formas democráticas de diálogo, tanto que Sarangerel informa o desejo de conviver com Júlio em Angola, cuja realização é a ética do amor.

Não à toa a chegada de Sarangerel se dá com o fim da guerra civil, e, aqui, se desenvolve a crítica ao Estado-nação e à postura da classe dirigente, que visava as multinacionais e o mercado estrangeiro europeu (PEPETELA, 2009, p. 180). Três anos depois, a morte atravessa o tempo e o amor, de maneira a esclarecer a pista dada neste trecho: "Nem imaginam quanto é bom não precisar fazer contas ao tempo, porque ele se tornou eterno ou inexistente" (2009, p. 151). À volta do sentido das narrativas póstumas e autobiográficas, as travessias de Júlio são baseadas no amor que não cede à corrupção. Logo, se não existe a preocupação com o tempo, o espaço permanece como um lugar de referência, "O Grande Sul. O Sul da minha vida." (2009, p. 188).

Dessa forma, a metáfora do Sul simboliza um lugar de diversidades e proposição de lógica outra aos paradigmas culturais, políticos e sociais provenientes das práticas do capitalismo colonial, sobretudo no domínio epistemológico e na inferiorização dos saberes dos grupos e sujeitos marginalizados. Nesse contexto, o Sul traz os saberes de muitas vidas, de proposições de mundos plausíveis, na narrativa, por uma interculturalidade dos espaços e do amor.

\section{Considerações finais: paratexto movente e relacional}

O ponto de partida de fechamento deste texto visa a seguinte questão: quais caminhos moventes e relacionais os paratextos sugerem? A premissa é a obra na formação artística, cultural e social, haja vista sua composição capaz de trazer informações, valorizações ou comentários. Os paratextos, como carregadores de dados sobre o fazer da obra literária, conjecturam relações de sentido que se completam no pacto entre autor, leitor e obra. O "autor-pessoa" é responsável pela construção da obra ${ }^{7}$, com a intenção de que ela seja lida; e, assim, o leitor dá vida ao texto quando traz interpretações possíveis.

A análise em tela partiu do "paratexto autoral" na orientação interpretativa dos elementos culturais, sociais e estéticos presentes em Mayombe e $O$ planalto e a estepe: Angola, dos anos 60 aos nossos dias. A história real de um amor impossivel. $\mathrm{O}$ "paratexto autoral" abriu um espaço de articulação com dois aspectos da narrativa: instância narrativa e espaço. Angola é a referência, ponto de partida e de retomada que representa um lugar de encontros, contatos e tensões. Assim, ao situar, de modo breve, o conceito-chave, passou-se à busca pela resposta à hipótese interpretativa.

${ }^{7}$ Cabe destacar que não desconsideramos a presença do editor no processo de organização e escolha dos elementos da obra. 
Nesse sentido, a definição do pseudônimo Pepetela como figura simbólica torna possível o projeto literário e, em consequência, a abertura às formas de narrar. Em Mayombe, a instância narrativa, entre narrar em terceira pessoa e em primeira pessoa, conecta as narrativas individuais à narrativa coletiva e propõe um espaço de convívio entre as diferenças. Já em $O$ planalto e a estepe, com os deslocamentos do narrador-personagem, estabelece-se o vínculo com a oralidade e os saberes tradicionais, sem excluir os contatos com outras culturas. Tão logo, com a percepção do narrador-trapeiro (GAGNEBIN, 2006), as duas obras evocam uma direção: as grandes narrativas são descentradas para a inserção das narrativas marginais.

Após a questão do nome do autor e do elo com os narradores, o título e as dedicatórias são definidos como discursos que orientam a análise do espaço nas duas obras (BRANDÃO, 2013). A representação de lugares, histórias e personagens não vistos antes permite a afirmação da cultura negra e uma sensibilidade outra sobre Angola. Não só isso, mas também a tensão com as fronteiras e os trânsitos dos narradores e personagens em torno dos espaços nacionais e transnacionais. Como a floresta simboliza o lugar fixo e as travessias aludem ao espaço movente e relacional, infere-se a presença de raízes e rotas na figuração do imaginário cultural angolano.

Para concluir, os elementos paratextuais são produtivos na ampliação do horizonte de expectativas da recepção das obras literárias. Eles surgem como via de contribuição aos trabalhos críticos das literaturas africanas de língua portuguesa e, até mesmo, à guisa de articulação com outras possibilidades investigativas, como um recurso para a investigação das geografias, entendidas, pois, como escritas de representação simbólicas de um espaço de convivência das diversas formas sociais e culturais. Formam-se, portanto, por um gesto de abertura movente e relacional.

\section{Referências}

BAKHTIN, Mikhail. O discurso no romance. In: BAKHTIN, Mikhail. Questões de literatura e de estética: a teoria do romance. Tradução de Aurora Fornomi Bernardini [et al.]. 7. ed. São Paulo: Hucitec; UNESP, 2014. p. 71-210.

BRANDÃO, Luís Alberto. Teorias do espaço literário. 1. ed. São Paulo: Editora Perspectiva, 2013.

CAN, Nazir Ahmed. Espaço fictício e situação-limite em narrativa de língua portuguesa. Gragoatá, Niterói, v.25, n. 53, p. 945-971, 2020.

CHAVES, Rita. A formação do romance angolano. São Paulo: Coleção Via Atlântica, 1999. 
GAGNEBIN, Jeanne Marie. Memória, história, testemunho. In: GAGNEBIN, Jeanne Marie. Lembrar, escrever, esquecer. 1. ed. São Paulo: Editora 34, 2006, p. 44-57.

GENETTE, Gérard. Paratextos Editoriais. Tradução de Álvaro Faleiros. 1. ed. São Paulo: Ateliê Editorial, 2009 [1987].

HALL, Stuart. A identidade cultural na pós-modernidade. Tradução de Tomaz Tadeu da Silva e Guacira Lopes Louro. 12. ed. Rio de Janeiro: Lamparina, 2015.

PEPETELA. O planalto e a estepe: Angola, dos anos 60 aos nossos dias. A história real de um amor impossível. São Paulo: Leya, 2009.

PEPETELA. Mayombe. São Paulo: Leya, 2013 [1980].

SECCO, Carmem Lúcia Tindó. A magia das letras africanas: ensaio sobre as literaturas de Angola, Moçambique e outros diálogos. 2. ed. Rio de Janeiro: Quartet, 2008.

SILVA, Rejane Vecchia da Rocha; MATTOS, Tatiane Reghini. Mayombe: presença da guerra, perspectiva histórica e memória na construção do romance. CERRADOS: Revista do Programa de Pós-Graduação em Literatura, n. 40, ano 24, p. 289-302, 2015. 